\title{
On the Origin of the Regioselective Hydrolysis of a Naphthoquinone Diacetate:
}

\section{A Molecular Orbital Study}

\author{
Ricardo L. Longo*, Ruth L. Nunes and Lothar W. Bieber \\ Departamento de Química Fundamental, Universidade Federal de Pernambuco, 50.740-540, Recife-PE, Brazil
}

\begin{abstract}
A seletividade observada (Nunes, R.L.; Bieber, L.W.; Longo, R.L. J. Nat. Prod. 1999, 62, 1600) na reação de hidrólise do diacetato de 2,5-dimetil-1,4-naftoidroquinona em condições reacionais brandas, meio básico, e que favorece a hidrólise do grupo 4-acetato, foi investigada utilizando métodos de ab initio e semiempíricos. Em fase gasosa (sistemas isolados) estes métodos não forneceram resultados consistentes com a seletividade observada. Com a inclusão dos efeitos do solvente (água) através do modelo de solvatação discreta no método semi-empírico AM1, foi possível estabelecer a estabilidade relativa dos intermediários tetraédricos e dos seus respectivos estados de transição como sendo a responsável pela seletividade observada. A origem da estabilidade relativa, e portanto, da seletividade está relacionada com as interação repulsivas entre o grupo substituinte 2-metil no anel do naftaleno e a metila do grupo 4-acetado, assim como o impedimento destes grupos à hidratação do grupamento iônico dos intermediários tetraédricos.
\end{abstract}

The regioselectivity found in the mild basic hydrolysis of the 2,5-dimethyl-1,4-naphthohydroquinone diacetate (Nunes, R.L.; Bieber, L.W.; Longo, R.L. J. Nat. Prod. 1999, 62, 1600) has been studied with $a b$ initio and semiempirical molecular orbital methods. In the gas phase (isolated systems), these methods were not able to provide results that could explain the observed selectivity. However, when the solvent effects were included in the AM1 method using the discrete solvation model it was possible to establish that this selectivity is due to the relative stability of the tetrahedral intermediates and their transitions states. The origin of this relative stability and thus of the observed selectivity is due to the repulsive interactions between the 2methyl substituent in the naphthalene ring and the methyl group in the 4-acetate substituent, as well as their hindrance towards the hydration of the ionic group in the tetrahedral intermediates.

Keywords: regioselectivity, MO calculations, solvent effects

\section{Introduction}

Base-promoted ester hydrolysis (saponification) has been used by the Phoenicians to make soap over 2000 years ago $^{1}$. Nowadays this reaction is employed in organic synthesis mainly for protecting/deprotecting hydroxyl groups. This reaction is also widely used in introductory organic chemistry laboratories in undergraduate courses. Despite this reaction being so old and useful some of its aspects are still elusive. For instance, during the synthesis of the natural product Mansonone $\mathrm{F}^{2}$ a remarkable regioselectivity has been found for the base-promoted hydrolysis of the 2,5-dimethyl-1,4-naphthohydroquinone diacetate intermediate. As shown in Scheme 1, the hydrolysis of (1) in mild basic aqueous/methanol media yielded the monoacetates in $84 \%$ yield in a proportion of $80: 20$ of the isomers (2):(3), according to an ${ }^{1} \mathrm{H}-\mathrm{NMR}$ analysis ${ }^{2}$.

\footnotetext{
*e-mail: longo@npd.ufpe.br
}

This selectivity had already been observed in the hydrolysis of other methyl-1,4-naphthohydroquinone diacetates $^{3,4}$ as well as been applied in the synthesis of natural products ${ }^{4}$. However, no attempt has been made to explain this selectivity, despite of its potential application in organic synthesis. Attempts to rationalize this selectivity based upon the relative stability of the products using resonance stabilization of enolate ions were unsuccessful. ${ }^{2}$ Consequently, quantitative theoretical approaches were used to study this reaction, namely, $a b$ initio and semiempirical molecular orbital (MO) methods. The computational modeling of this reaction is not trivial if the solvent effects have to be considered, because several groups of the reactants or intermediates are polar and/or ionic, and the solvent is highly polar (water/methanol). Thus, the specific interactions, namely, hydrogen bonds have to be described accurately. In addition, apolar methyl groups are present, so that their hydrophobic interactions also have to be considered properly. 
<smiles>CC1=CC(=O)c2c(I)cccc2C1=O</smiles><smiles>COc1cc(C)c([N+](=O)[O-])c2cccc(C)c12</smiles><smiles>C1CCCCC1</smiles>

(1)<smiles>Cc1c2occ(C)c3cc(C)c4ccc(C)c(c(=O)c1=O)c4c3-2</smiles><smiles>COc1c(C)cc(O)c2c(C)cccc12</smiles>

(2)<smiles>COc1cc(C)c(O)c2cccc(C)c12</smiles>

(3)

Scheme 1.

The reaction mechanisms for the hydrolysis of carboxylic esters can be classified, according to Ingold 5 , as BAC1 and BAC2 for acyl cleavage and BAL1 and BAL2 for alkyl cleavage. In basic aqueous/organic media the BAC2 is the predominant mechanism and involves a tetrahedral intermediate originated from the attack of the carbonyl group by the hydroxyl ion 6,7 . Spectroscopic detection, ${ }^{18} \mathrm{O}$ labeling and isolation procedures, as well as thermodynamic and kinetic data have provided compelling evidence for the existence of this intermediate $^{7,8}$. In the gas phase, nucleophilic attacks to carboxylic esters take a different course, with the BAL2 mechanism being the observed one ${ }^{6}$. However, when the nucleophile is solvated, even by a single solvent molecule, the BAC2 mechanism is also observed ${ }^{6}$. Thus, the proper description of the solvent effects is essential to model this selectivity and to understand its origin.

\section{Theoretical Procedure}

All calculations were performed on a Sun UltraSparc1 under Solaris 2.25 workstation. For the $a b$ initio calculations ${ }^{9,10}$ the GAMESS program ${ }^{11}$ was used with the standard basis sets $3-21 \mathrm{G}^{12}$ and its counter part effective core potential $(\mathrm{SBK})^{13}$ augmented by an $s$-type diffuse function ${ }^{14}$ on the oxygen atoms of the $o$-naftoquinone ring. For the semiempirical calculations the MOPAC 93 (revision 2) program $^{15}$ was used with the standard Hamiltonians $\mathrm{MNDO}^{16}, \mathrm{AM}^{17}$ and $\mathrm{PM} 3^{18}$. All geometry optimizations were performed in Cartesian coordinates without any restriction, except in the reaction coordinate calculations. The convergence threshold for all geometry optimization calculation was $5 \times 10^{-3} \mathrm{~kJ} \mathrm{~mol}^{-1} \mathrm{pm}^{-1}$. All the extreme points in the potential energy surface have been characterized by the calculation of the Hessian eigenvalues. The ORTEP-III program $^{19}$ was used for visualization of the molecular structures. The discrete model ${ }^{20}$ described the solvent effects; namely, 18 water molecules surrounded the tetrahedral intermediates. In fact, initially only a few water molecules were placed at hydrogen bond distances from the oxygen atoms and the AM1 method were used to optimize the geometry. Then, the solvent positions were modified at random generating approximately 20 structures which had their geometry fully optimized. Only the structures within $12 \mathrm{~kJ} \mathrm{~mol}^{-1}$ from the most stable one were used in the sequence, which involved the inclusion of more water molecules until it reached 18 molecules. At each step of including these water molecules a complete optimization of the molecular structure was performed.

\section{Results and Discussion}

Considering the Hammond's postulate ${ }^{6}$, the selectivity of the diacetate hydrolysis was initially explored by calculating the relative stability of the phenolate formed in C-1 and C-4 using the semiempirical methods MNDO ${ }^{16}$, $\mathrm{AM} 1^{17}$ and $\mathrm{PM} 3^{18}$. From Table 1 it can be seen that these methods have not provided any corroboration of the relative stability predicted by the inductive effects of the methyl groups. Also, these results are in disagreement with the observed selectivity, despite the relative energy calculated by the AM1 method being very small, but still positive.

As a result, $a b$ initio MO calculations ${ }^{9,10}$ were also performed for both phenolates. With both basis sets (SBK and 3-21G) Hartree-Fock (HF) calculations indicated that the phenolate at $\mathrm{C}-1$ is about $7.7 \mathrm{~kJ} \mathrm{~mol}^{-1}$ more stable than that at $\mathrm{C}-4$, in agreement with the experimental observation. However, when electron correlation effects were included via second order perturbation theory (MP2) this relative stability was inverted to approximately $-3.0 \mathrm{~kJ} \mathrm{~mol}^{-1}$. It should be noted that the geometry of the anions has not been optimized at the MP2 level. However, the point is 
that even for the correct stability trend obtained by the HF calculations, the energy differences are much too small to explain the high selectivity of the diacetate hydrolysis reaction. Thus, the complete reaction mechanism for this hydrolysis, including the solvent effects, has been studied via the AM1 method.

Table 1. Total energy and relative stability of the phenolates of $\mathbf{1}$ at $\mathrm{C}-1$ and $\mathrm{C}-4$

\begin{tabular}{lccc}
\hline & \multicolumn{2}{c}{$\begin{array}{c}\text { Phenolate total } \\
\text { energy }(\mathrm{eV})^{\mathrm{a})}\end{array}$} & Relative Energy \\
\hline Method & at C-1 & at C-4 & $\left(\mathrm{kJ} \mathrm{mol}^{-1}\right)$ \\
\hline AM1 & -2934.0521 & -2934.0368 & +1.46 \\
MNDO & -2941.7642 & -2941.6542 & +10.6 \\
PM3 & -2741.7411 & -2741.7186 & +2.18 \\
HF/SBK//HF/SBK & -3568.6886 & -3568.7569 & -6.61 \\
MP2/SBK//HF/SBK & -3607.0460 & -3607.0156 & +2.93 \\
HF/3-21G//HF/3-21G & -20628.840 & -20628.911 & -6.74 \\
MP2/3-21G//HF/3-21G & -20672.218 & -20672.208 & +0.96 \\
\hline
\end{tabular}

a) $1 \mathrm{eV} \approx 96.487 \mathrm{~kJ} \mathrm{~mol}^{-1}$

Table 2. AM1 enthalpy of formation and activation enthalpy $\left(\mathrm{kJ} \mathrm{mol}^{-1}\right)$

\begin{tabular}{lccc}
\hline Species & position & $\begin{array}{c}\text { Enthalpy of } \\
\text { Formation }\end{array}$ & $\begin{array}{c}\text { Activation } \\
\text { Enthalpy }\end{array}$ \\
\hline $\begin{array}{l}\text { Tetrahedral intermediate } \\
+3 \mathrm{H}_{2} \mathrm{O}\end{array}$ & $\mathrm{C}-1$ & -1851.42 & \\
$\begin{array}{l}\text { Tetrahedral intermediate } \\
+3 \mathrm{H}_{2} \mathrm{O}\end{array}$ & $\mathrm{C}-4$ & -1854.35 & \\
$\begin{array}{l}\text { Transition State }+3 \mathrm{H}_{2} \mathrm{O} \\
\text { Transition State }+3 \mathrm{H}_{2} \mathrm{O}\end{array}$ & $\mathrm{C}-1$ & -1805.81 & 45.61 \\
$\begin{array}{l}\text { Tetrahedral intermediate } \\
+18 \mathrm{H}_{2} \mathrm{O}\end{array}$ & $\mathrm{C}-1$ & -1809.16 & 45.19 \\
$\begin{array}{l}\text { Tetrahedral intermediate } \\
+18 \mathrm{H}_{2} \mathrm{O}\end{array}$ & $\mathrm{C}-4$ & -6064.29 & \\
Transition State $+18 \mathrm{H}_{2} \mathrm{O}$ & $\mathrm{C}-1$ & -6047.13 & 17.16 \\
$\begin{array}{l}\text { Transition State }+18 \mathrm{H}_{2} \mathrm{O} \\
\mathrm{C}\end{array}$ & $\mathrm{C}-4$ & -6059.69 & 18.00 \\
\hline
\end{tabular}

The structure and energetics of the tetrahedral intermediate at C-1 and C-4 formed from the hydroxide addition to each carbonyl group has been calculated by the AM1 method. It has been found that the tetrahedral intermediates are not minima in the potential energy surfaces. This result is consistent with experimental ${ }^{21}$ and theoretical ${ }^{22,23}$ data that lead to a double or triple well in the reaction profile in the gas phase, where the tetrahedral species is either a transition state or an unstable intermediate. Upon the inclusion of the solvent effects the tetrahedral species became an intermediate for the hydrolysis reaction in solution $^{22,23}$. Since these tetrahedral intermediates are ionic and contain polar groups, and the solvent is a mixture of water and methanol, the most appropriate approach for including the solvent effects would be a discrete model. In the present case, 18 water molecules surrounded both tetrahedral intermediates. It should be noted that only three water molecules surrounding the ionic site were enough to stabilize the tetrahedral intermediates, so that they became true minimum in the potential energy surface. However, to achieve convergence in the relative energy and activation enthalpy more than 12 water molecules were necessary, so that 18 water molecules were used to guarantee convergence. As shown in Table 2 the tetrahedral intermediate at C-4 is about $12.5 \mathrm{~kJ} \mathrm{~mol}^{-1}$ more stable than the one at $\mathrm{C}-1$, in agreement with the observed selectivity, despite the relative stability in the gas phase being the reverse.

The reaction profiles for the hydrolysis (forward) and for the reverse (diacetate formation) reactions were calculated and are shown in Figures $1 \mathrm{a}$ and $1 \mathrm{~b}$, respectively. The forward reaction (hydrolysis) has a small activation energy and is highly exothermic, characterizing an irreversible reaction, and also explaining the high yield of this hydrolysis. The Hammond's principle ${ }^{6}$ states that the transition state energy is directly related to tetrahedral intermediate enthalpy of formation. Indeed, from Table 1 it is shown that the transition state of the hydrolysis reaction at $\mathrm{C}-4$ is also about $13 \mathrm{~kJ} \mathrm{~mol}^{-1}$ lower in energy than that at C-1 (Figure 1a). Thus, the origin of the regioselectivity for the hydrolysis of the diacetate $\mathbf{1}$ is related to the relative stability of the tetrahedral intermediates, and to the maintenance of this stabilization in the transition state formed from the nucleophilic addition of the hydroxide to the carbonyl groups.

This relative stability is dependent upon the interaction between the substituents in the naphthalene ring and the acetates, as well as the solvation effects of a polar solvent. The formation of the tetrahedral intermediate at C-1 leads to a conformational change of the acetate group. This causes a large repulsive interaction between the methyl group at the naphthalene at C-2 with the methyl group at the acetate group (241 - $248 \mathrm{pm})$. This steric hindrance are not significantly present in the tetrahedral intermediate at C-4 because the methyl group at C-5 is quite far from the acetate methyl group (270 - 285 pm), as can be seen in Figures 2a and $2 \mathrm{~b}$, respectively. The close proximity of the methyl groups in the intermediate at $\mathrm{C}-1$ also hinders its hydration causing a destabilization relative to the tetrahedral intermediate at C-4. It thus can be concluded that the origin of the observed selectivity is due to the interactions between the substituents in the naphthalene ring and in the ester, as well as their relative hindrance towards the solvation of the ionic group. 


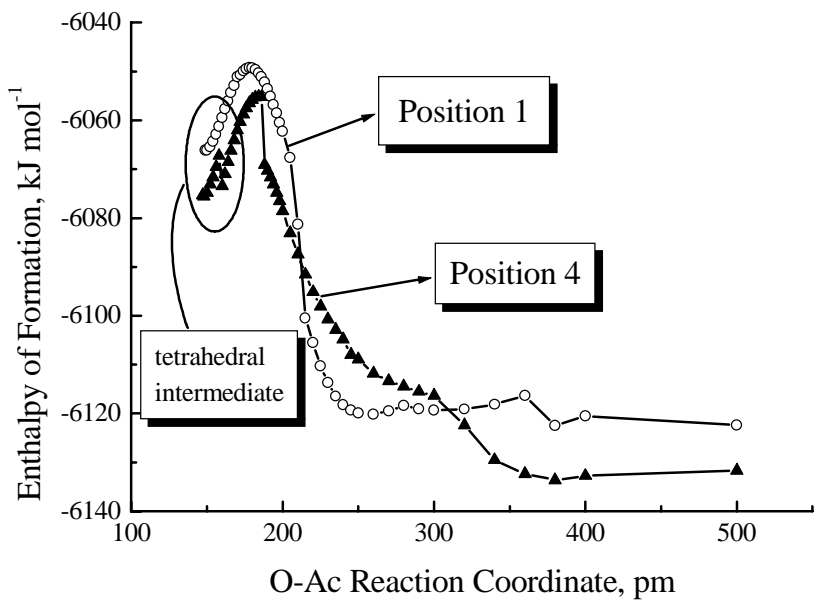

(a)

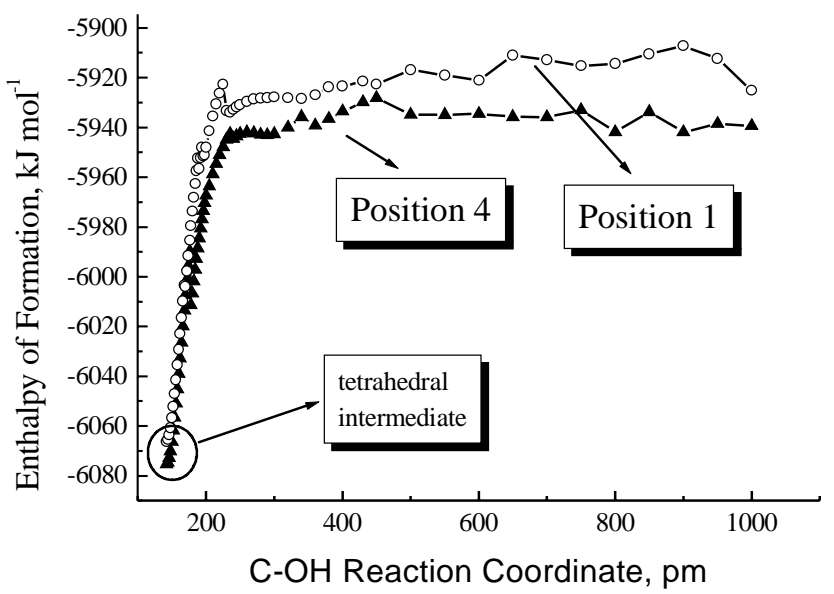

(b)

Figure 1. Reaction profile of the (a) forward reaction (hydrolysis) and of the (b) reverse reaction.

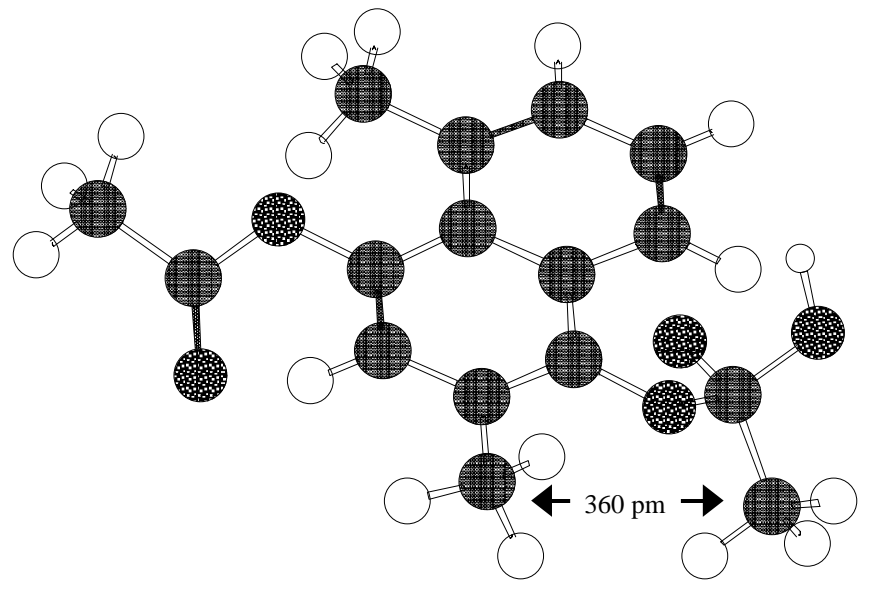

(a)

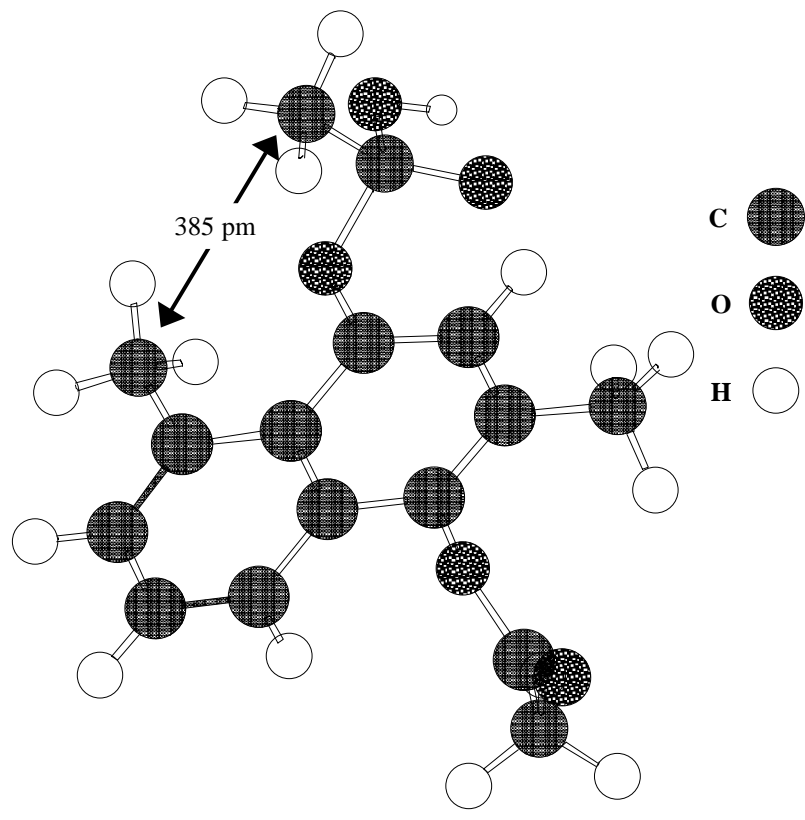

(b)

Figure 2. Structure of the hydrated tetrahedral intermediates at C-1 (a) and in C-4 (b). The hydration molecules are not shown for simplicity.

\section{Conclusions}

The present model (AM1 + discrete solvent molecules) can provide a semi-quantitative account of the observed selectivity of basic hydrolysis of diacetates. The origin of the regioselectivity for the hydrolysis of the diacetate is related to the relative stability of the tetrahedral intermediates. Steric interactions between the substituents in the naphthalene ring and the acetate substituent and the solvation effects are responsible for the relative stabilization of the tetrahedral intermediates.

\section{Acknowledgments}

The authors thank the Brazilian funding agencies: FINEP, FACEPE, CAPES, CNPq and PADCT for financial support. One of the authors (RLN) wishes to acknowledge the fellowship from CNPq.

\section{References}

1. Carey, F.A. Organic Chemistry, McGraw-Hill, New York, 1987, page 798. 
2. Nunes, R. L.; Bieber, L. W.; Longo, R. L. J. Nat. Prod. 1999, 62, 1600.

3. Baker, B. R.; Davies, T. H.; McElroy, L.; Carlson, G. H. J. Am. Chem. Soc. 1942, 64, 1100.

4. Grant, H. N.; Prelog, V.; Sneeden, R. P. A. Helv. Chim. Acta 1963, 46, 415.

5. Ingold, C. Structure and Mechanism in Organic Chemistry, 2nd ed.; Cornell University Press, Ithaca, NY, 1969.

6. March, J. Advanced Organic Chemistry, 4th ed.; John Wiley \& Sons; New York, 1992.

7. Bender, M. L. Chem. Rev. 1960, 60, 53.

8. Bender, M. L.; Heck, H. d'A. J. Am. Chem. Soc. 1967, 69, 1211.

9. Hehre, W. J.; Radom, L.; Schleyer, P. vR.; Pople, J. A. Ab Initio Molecular Orbital Theory; John Wiley \& Sons, New York, 1986.

10. Clark, T. A Handbook of Computational Chemistry; John Wiley \& Sons, New York, 1985.

11. Schmidt, M. W.; Baldridge, K. K.; Boatz, J. A.; Elbert, S. T.; Gordon, M. S.; Jensen, J. H.; Koseki, S.; Matsunaga, N.; Nguyen, K. A.; Su, S. J.; Windus, T. L.; Dupuis, M.; Montgomery, J. A. J. Comput. Chem. 1993, 14, 1347.
12. Binkley, J. S.; Pople, J. A.; Hehre, W. J. J. Am. Chem. Soc. 1980, 102, 939.

13. Stevens, W. J.; Basch, H.; Krauss, M. J. Chem. Phys. 1984, 81, 6026.

14. Clark, T.; Chandrasekhar, J.; Spitznagel, G.W.; Schleyer, P.vR. J. Comput. Chem. 1983, 4, 294.

15. Stewart, J. J. P. MOPAC 93.00 Manual; Fujitsu Limited, Tokyo, Japan, 1993.

16. Dewar, M. J. S.; Thiel, W. J. Am. Chem. Soc. 1977, 99, 4899.

17. Dewar, M. J. S.; Zoebisch, E. G.; Healy, E. F.; Stewart, J. J. P. J. Am. Chem. Soc. 1985, 107, 3902.

18. Stewart, J. J. P. J. Comput. Chem. 1989, 10, 210.

19. Burnett, M. N.; Johnson, C. K. ORTEP-III; Oak Ridge National Laboratory, Oak Ridge, TN, USA, 1996.

20. Freitas, L. C. G.; Longo, R. L.; Simas, A. M. J. Chem. Soc., Faraday Trans. 1992, 189.

21. Wilbur, J. L.; Brauman, J. I. J. Am. Chem. Soc. 1994, 116, 5839; 1994, 116, 9216.

22. Madura, J. D.; Jorgensen, W. L. J. Am. Chem. Soc. 1986, 108, 2517.

23. Blake, J. F.; Jorgensen, W. L. J. Am. Chem. Soc. 1987, 109, 3856.

Received: February 1, 2000

Published on the web: October 25, 2000 